\title{
Growth and Photosynthetic Characteristics of Two Strawberry Cultivars in Response to Furostanol Glycosides Treatments
}

\author{
Raluca Petronela CĂUlEṬ’, Aliona MORARIU', Dorina IUREA², Gică GRĂDINARIU* \\ ${ }^{1}$ University of Agricultural Sciences and Veterinary Medicine "Ion Ionescu de la Brad", Faculty of Horticulture, \\ 3 M. Sadoveanu Alee, 700490,Iasi, Romania; ggradin@uaiasi.ro ("corresponding author) \\ ${ }^{2}$ Biological Research Institute, 47 Lascar Catargi Street, Iasi, Romania
}

\begin{abstract}
Furostanol glycosides represent a large group of steroid compounds of plant origin with a broad spectrum of biological activities (anabolic, antioxidant, anti-fungal and nematicidal). Most of the research exhibits this effect in stress induced response on different pathogen attacks and only a few studies show the effect of glycoside on plants growth and development. In order to investigate the effects of furostanol glycoside treatment on rooting, growth performance and photosynthetic system efficiency, young unrooted strawberry plants (cv. 'Real' and 'Magic') were immersed in different concentrations ( $0.03 \mathrm{mM}, 0.3 \mathrm{mM}, 3 \mathrm{mM})$ of G1 solution (glycoside extracted from Lycopersicon sp.) and G2 (extracted from Digitalis sp.) and morphometric parameters were determined. The results showed that immersion in $0.3 \mathrm{mM}$ glycoside solution improved the quality of strawberry planting material by increasing the number and length of roots, as well as by stimulating formation of new leaves. Moreover, the influence of foliar spraying with G1 and G2 on plants growth, assimilator pigments content and photosynthesis was determined. Foliar spraying with both glycosides solutions improved radicular growth and development, but dimensions of foliar apparatus increased only in G1 treated variants. Although both glycoside treatments induced an increase in assimilator pigments content, photosynthetic rate decreased as a consequence of stomatal limitations associated with better efficiency of water use and of internal $\mathrm{CO}_{2}$, which suggests that these chemicals may have an antitranspirant action.
\end{abstract}

Keywords: antitranspirant, assimilator pigments, leaves, photosynthesis, roots

\section{Introduction}

Strawberry (Fragaria $\times$ ananasa Duch.) cultivation has an important economic and nutritional interest due to its high production potential and fruits quality i.e., rich in vitamin C, manganese, potassium, folic acid, anthocyanins, flavonols and flavonoids which, due to its antioxidant action, plays an important role in preventing neuronal and cardiovascular diseases, even diabetes or cancer.

The economic profitability of this species resides in its ecological plasticity, productivity and precocity that allows extra-seasonal crops, according to the culture technology utilized.

More and more in the last decade, ecological farms have been using environmentally friendly production methods to improve plants yield and fruit quality. A real challenge in ecological fruit production is the reduction of chemical fertilization and some other chemical treatments for pests and disease control. In this direction, scientists actively search for compounds of plant origin that are natural adaptors and do not disturb plants ecological balance. It is supposed that the adaptive effect of some natural compounds is associated with their influence on the state of the lipid components of cell membranes. In light of this, the most promising compounds are steroid glycosides of the furostanol series (Vasil'eva et al., 2005).
Furostanol glycosides represent a large group of steroid compounds of plant origin with a broad spectrum of biological activity. There are many papers related to a great number of compounds belonging to furostanol glycosides which make use of methods of isolation and characterisation (Arthan et al., 2006; Kirmizibekmez et al., 2002; Napolitano et al., 2011; Peng et al., 1995; Yahara et al., 1994) but only few of them mention their specific effect on different organisms. Several studies show that furostanol glycosides may have anabolic (Aswar et al., 2010) antioxidant (Volkova et al., 2007), anti-fungal (Liu et al., 2003) and nematicidal activities (Vasil'eva et al., 2005).

The adaptive effect of furostanol glycosides in biotic stress was first discovered in tomatoes and cucumber plants infested with gull nematode. Activating the general nonspecific systems of stress response, furostanol glycosides extracted from Dioscorea deltoidea facilitated the activation of specialized mechanisms of long-term adaptation, which allowed plants to have an increased resistance to biotic stress conditions for an extended period of time (Vasil'eva et al., 2005).

Most of the research related to the role of furostanol glycoside in plants states its effect in stress induced response on different pathogens attack and only a few studies show the effect of glycoside on plants growth and development. According to Munteanu et al. (2008), furostanol glycoside 
232

extracted from seeds of Lycopersicon sp. and Capsicum sp., applied by foliar spraying, has stimulative effect on vegetative growth and increase photosynthetic pigment content in grapevine and apple trees. The hypothesis that glycoside treatments may improve photosynthetic efficiency was also put forward.

Therefore the purpose of this study was to determine the influence of furostanol glycoside treatments on both young and mature strawberry plants growth and to evaluate the possible changes in photosynthetic activity and chlorophylls content.

\section{Materials and methods}

Experiments were conducted in the greenhouse of Horticulture Faculty of Iasi, Romania. The two glycosides, provided by the Biological Research Institute from Iasi, were extracted and purified from seeds of Lycopesicon sp.G1 $(M=1082)$ and leaves of Digitalis sp. G2 $(M=1230)$. Their influence on strawberry growth and development was studied in two separate experiments.

The first experiment was made in order to determine the optimum glycoside concentration from the two treatment solutions and to evaluate the effect of glycoside treatment on planting material quality of two strawberry cultivars ('Real' and 'Magic'). Therefore, unrooted daughter plants (central bud and 1-2 leaves) were immersed in $3 \mathrm{mM}, 0.3 \mathrm{mM}$ and $0.03 \mathrm{mM}$ glycoside solution for one hour and planted in pots, in a mixture of soil: sand: litter in $(1: 1: 1, \mathrm{v}: \mathrm{v}: \mathrm{v})$.

The experiments were carried out in the greenhouse and for each variant three replications (10 plants/replication) were used. Photosynthetic active radiation (PAR) was $400-500 \mu \mathrm{mol} \mathrm{m} \mathrm{s}^{-1}$, relative humidity $52 \%$ temperature $22-23^{\circ} \mathrm{C}$ and $\mathrm{CO}_{2}$ concentration $380 \mu \mathrm{mol} \mathrm{mol}^{-1}$. Plant material quality was evaluated by morphometric measurements: rooting percentage, number and length of roots and number of new leaves.

The second experiment was focused on determining the influence of glycoside treatments (G1 and G2) on growth, photosynthesis and assimilator pigments accumulation in mature strawberry plants. Biologic material was represented by mature plants, (4-5 leaves) from 'Real' and 'Magic' varieties, previously acclimated at greenhouse conditions (similar with those described in the above experiment).

Glycoside treatments were applied by foliar spraying twice a week with $0.3 \mathrm{mM}$ solution; control plants were sprayed with distilled water. After one month the effect of furostanol glycosides on photosynthesis and chlorophyll pigments accumulation was evaluated.

Photosynthetic rate $(\mathrm{A})$, stomatal conductance $\left(\mathrm{g}_{\mathrm{s}}\right)$, transpiration rate $(\mathrm{E})$ and other parameters were measured using infrared gas analyser (LCi 600, ADC BioScientific Ltd., England) on fully uppermost expanded leaves at saturation light intensity on six plants from each replicate.
For determinations of the assimilator pigments, the youngest fully expanded leaf was collected the same day when gas exchange measurements were made. The total chlorophylls (Chl) and carotenoids (Car) were extracted with $80 \%$ acetone. The absorbance was measured on the T70 UV/VIS spectrophotometer and the amount of pigments was calculated according to the equations of Lichtenthaler (1987) method, while results were reported to dry weight.

At the end of experiment total leaf area, root length, and newly developed leaves and roots were determined. For leaf area measurements Image J software for Windows was used.

For each variant 5 plants were used and results are reported as the mean \pm standard error (SE) values of three independent experiments, measuring at least three different replicates (plants) in each experiment, followed by Duncan's t-test at $p<0.05$ for separation of differences between means. Tests assume equal variances and are adjusted for all pairwise comparisons within a row of each innermost suitable using the Bonferroni correction.

\section{Results and discussion}

Plants growth stimulators are frequently used in vegetative propagation to promote rooting and thereby to enhance plants growth and development. In our experiments rooting percentage was about $90-92 \%$ in all of the variants, however, a significant influence of glycoside treatments has nevertheless been observed.

After 4 weeks of growth, both furostanol glycoside treatments induced a better growth of the radicular system and leaves compared to the control (Fig. 1). The results showed that glycoside treatments improved new roots formation (Fig. 1A) up to 37\% (at 'Real' cultivar treated with G1 $0.3 \mathrm{mM}$ ) and their elongation (Fig. 1B) by 16$18 \%$ and increased the number of new leaves per plant up to $26 \%$ (Fig. 1C).

Glycoside concentration significantly $(p<0.05)$ influenced all morphometric traits (Fig. 1). Irrespective of glycoside type, maximum increase in roots number (by $37 \%$ at 'Real' and by $27 \%$ at 'Magic') has been recorded at plants sprayed with $0.3 \mathrm{mM}$ glycoside solution, while both $3 \mathrm{mM}$ and $0.03 \mathrm{mM}$ concentrations produced statistically similar results to those obtained in the control.

Interdependency of treatments action and concentrations has been demonstrated for strawberry by many researchers (Botta et al., 2009; Laugale et al., 2006; Sas-Paszt et al., 2008; Sarli et al., 2009). Results of other experiments have shown that the effect of the treatment increases with concentration until it reaches a maximum, after which it starts to decline (Rosier and Frampton, 2004). The 0.3 $\mathrm{mM}$ has been shown to be the optimal concentration in both glycosides treatments; therefore this concentration was used in further experiments. 
Likewise, the growth parameters were differentially affected by the glycoside type (Fig. 1A). Irrespective of cultivar our results pointed out that the use of G1 treatments induced a stronger increase in number of roots per plant (37\% G1 vs 29\% G2 at 'Real') (and 27\% G1 compared to 20\% G2 at 'Magic'), and this effect has also been observed on root length (Fig. 1B). Although not directly comparable, the present results are highly similar to those of $\mathrm{Ba}$ nón et al. (2003) and Górnik et al. (2008), who reported increases in root system growth in their experiments with different biostimulants.

The new leaves development has been slightly influenced by the glycoside type used with the 'Magic' cultivar, (which recorded 4\% more leaves in G1 treated plants than in G2 treated ones), but no effect has been recorded with 'Real', (Fig. 1A). An increase in leaves number/plant has been also observed with strawberry (Neri et al., 2002) and vegetables (Boehme et al., 2005) treated with seaweed extracts. Therefore we suppose that our furostanol glycosides may have stimulative effects in plants growth and development.

The two varieties reacted similarly to glycoside treatments by increasing their roots number per plant as well as their length and number of new leaves. Irrespective of glycoside type, a better growth of the radicular system has been observed with Real, which recorded a $10 \%$ higher increase in roots' number/plant than 'Magic'. However, the latter recorded a better development of foliar apparatus than 'Real', by increasing the mean new leaves number by $10 \%$ in G1 treated plants and by $5 \%$ in G2 treated ones.

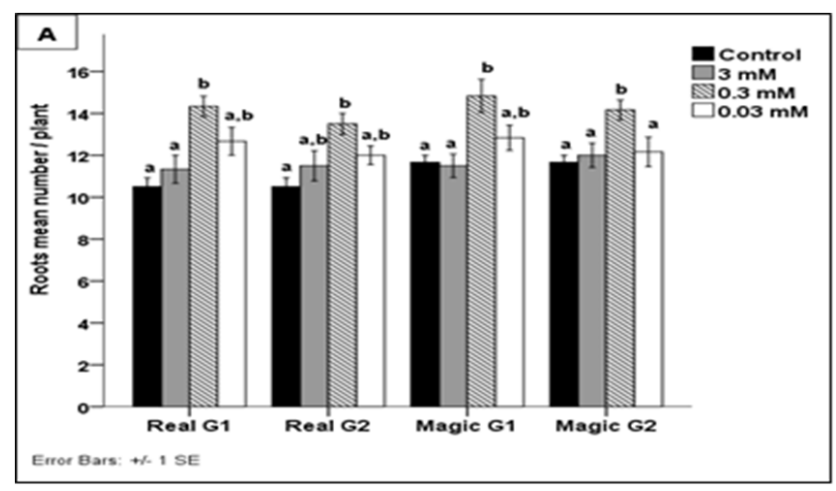

In the second experiment, furostanol glycosides were applied by foliar spraying on mature plants cultivated in pots. It is well known that plant response to different treatments varies from a different vegetation stage to another (Aminifard et al., 2010). The results obtained showed that the stimulating effect on radicular system growth was also maintained in adult plants, although increases in roots number and length were $30 \%$ smaller than those recorded in young treated plants.

Glycoside treatments increased significantly the number of new roots per plant (up to 25\%) (Fig. 2A), but did not induce any modification in root length. It has been observed that in both cultivars G1 treated plants had 5\% more roots than G2 treated ones (Fig. 2B).

The effect of furostanol glycosides treatments on foliar apparatus growth and development was different and dependent on glycoside type. Treatments with G1 (extracted from Lycopersicon sp.) enhanced new leaves formation (up to 23\%) (Fig. 2C) and increased leaf area (Fig. 2E) (up to $30 \%$ ) but reduced the leaf mean length up to $10 \%$ (Fig. 2D).

Treatments with G2 (extracted from Digitalis sp.) had no influence on new leaves number (Fig. 2C), but reduced leaf length more than G1 (by 15\%) (Fig. 2D) and decreased leaf area by $10-20 \%$ (Fig. 2E). It seems that G2 effect depends on vegetation stage and application on mature plants may induce some changes in hormonal balance which determine root growth and diminish leaves growth and leaf area. Similar results have been obtained by Deyton et al. (1991) for strawberry and Christov et al. (1995) for grapevine treated with paclobutrazol.

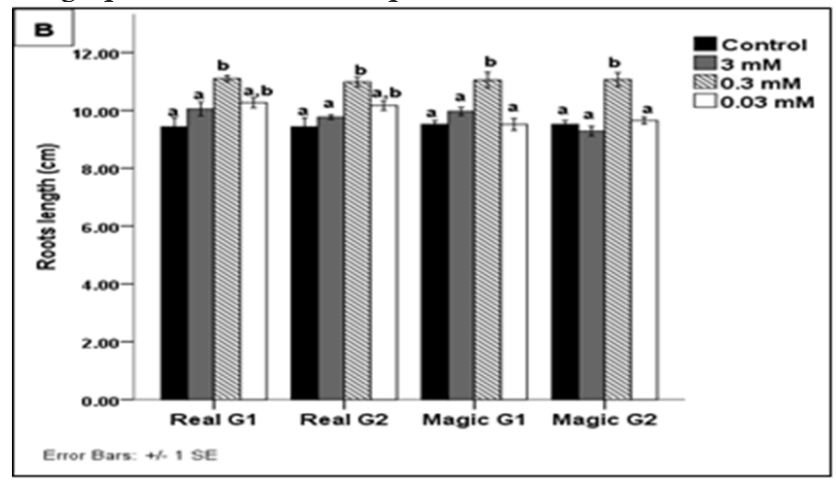

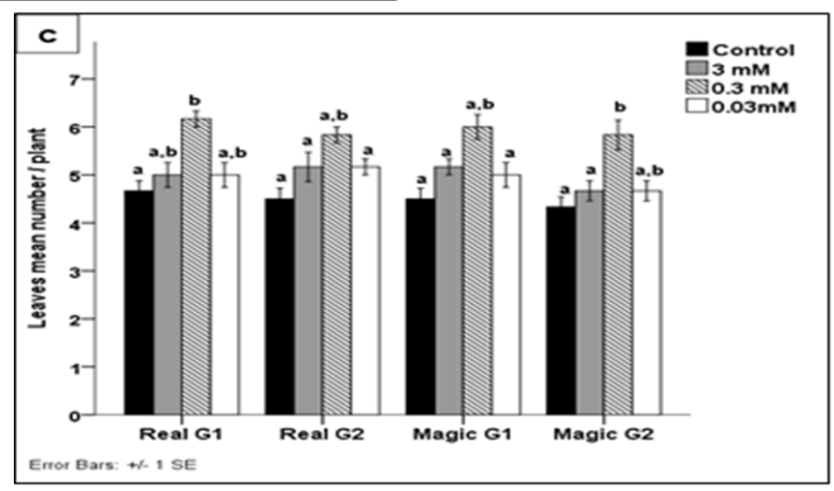

Fig. 1. Glycoside treatment influence on young strawberry plants

A-Roots mean number/plant, B-roots mean length, C-New leaves mean number / plant 
234

The induced changes in plants growth depend on studied genotype. With 'Real' cultivar, both G1 and G2 treatments determined a $6 \%$ increase in roots number per plant compared to 'Magic'. Moreover, in G1 treated variants 'Real' developed more leaves (up to 15\%), with a larger leaf area (up to $10 \%$ ), suggesting that 'Real' responded better than 'Magic' to glycoside treatments.

Moreover, glycoside treated plants exhibited a darker green colour than untreated ones due to $6-10 \%$ increase
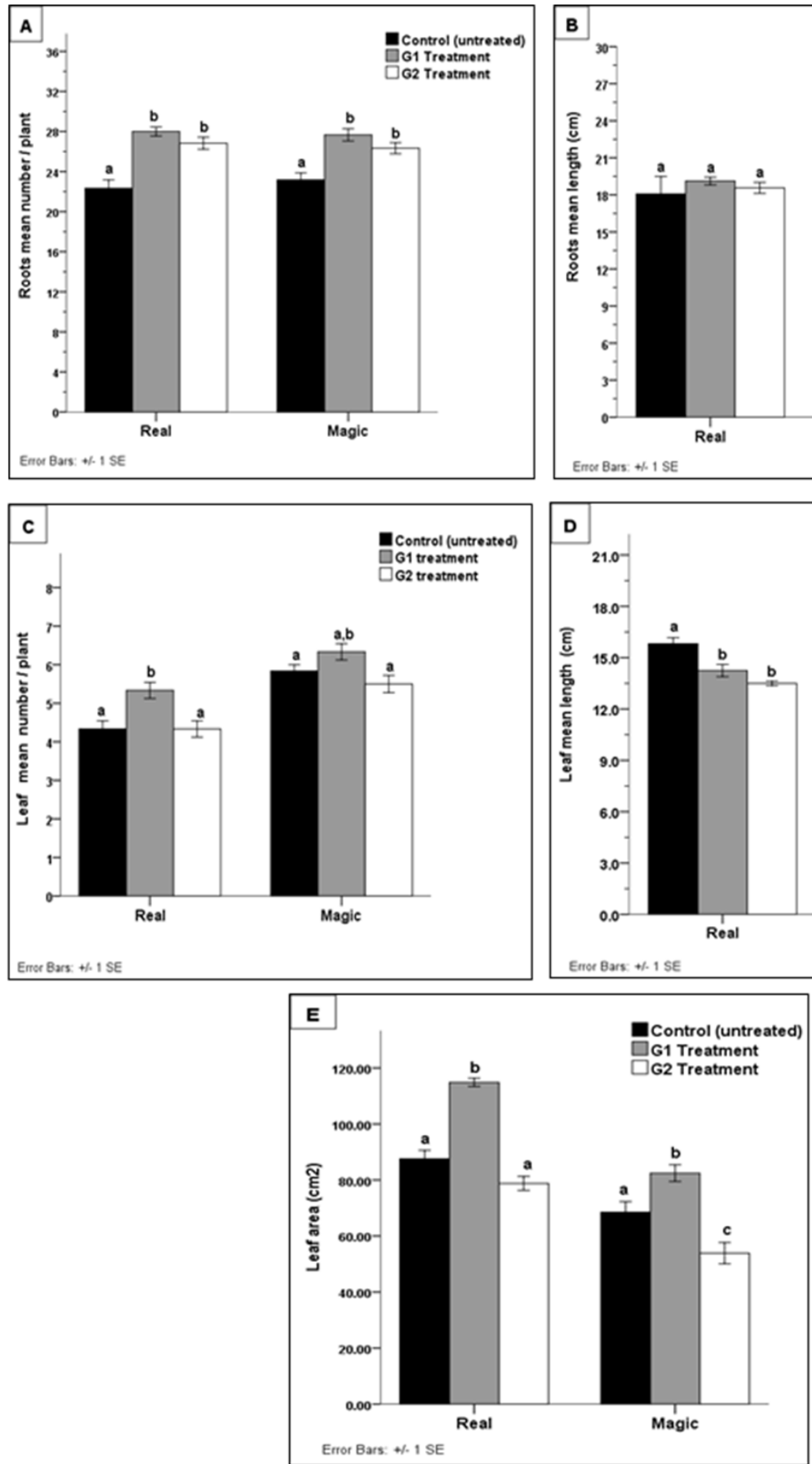

Fig. 2. Influence of glycoside treatments on mature strawberry plants growth

A-Roots' mean number/plant, B-Roots' mean length, C-New leaves' mean number / plant, D-Leaves' mean length, E-Leaf area

in total chlorophyll content. An increase in chlorophyll content has also been reported in experiments with biosimulators (Blunden et al., 1997) and may be attributed to an enhanced chlorophyll synthesis (Sebastian et al., 2002) and/or more densely packed chloroplasts per unit leaf area (Khalil, 1995).

Chlorophyll a and b levels were not equally sensitive to glycoside treatment. Chlorophyll b increased by $15 \%$ comparing with control, while chlorophyll a increased
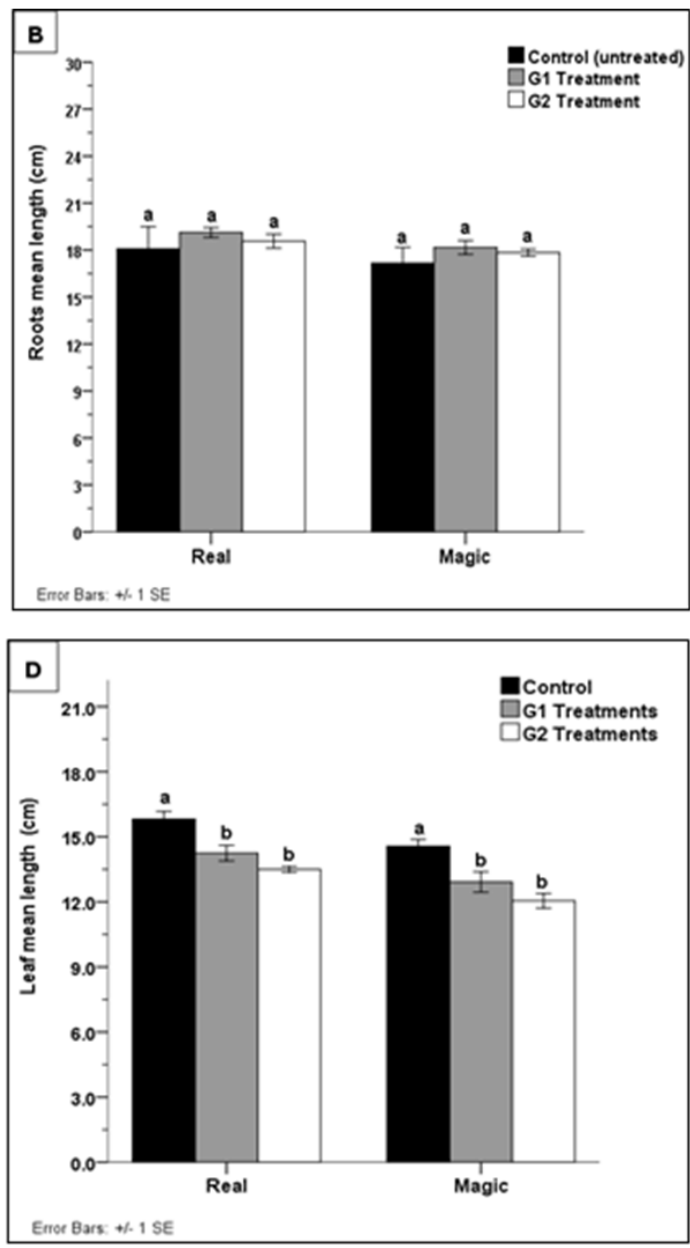
only by $9 \%$. Consequently, chlorophyll a/chlorophyll b ratio (Tab. 1) decreased by 5-7\% in G1 treated variants and by $8 \%$ in $\mathrm{G} 2$ treated plants.

Carotenoid pigments increased by $23-30 \%$ in G1 treated plants, and by $12-16 \%$ in G2 treated ones. Several other studies also report increases in carotenoid pigments content in plants treated with seaweed extracts (Pise and Sabale, 2010; Thirumaran et al., 2009).
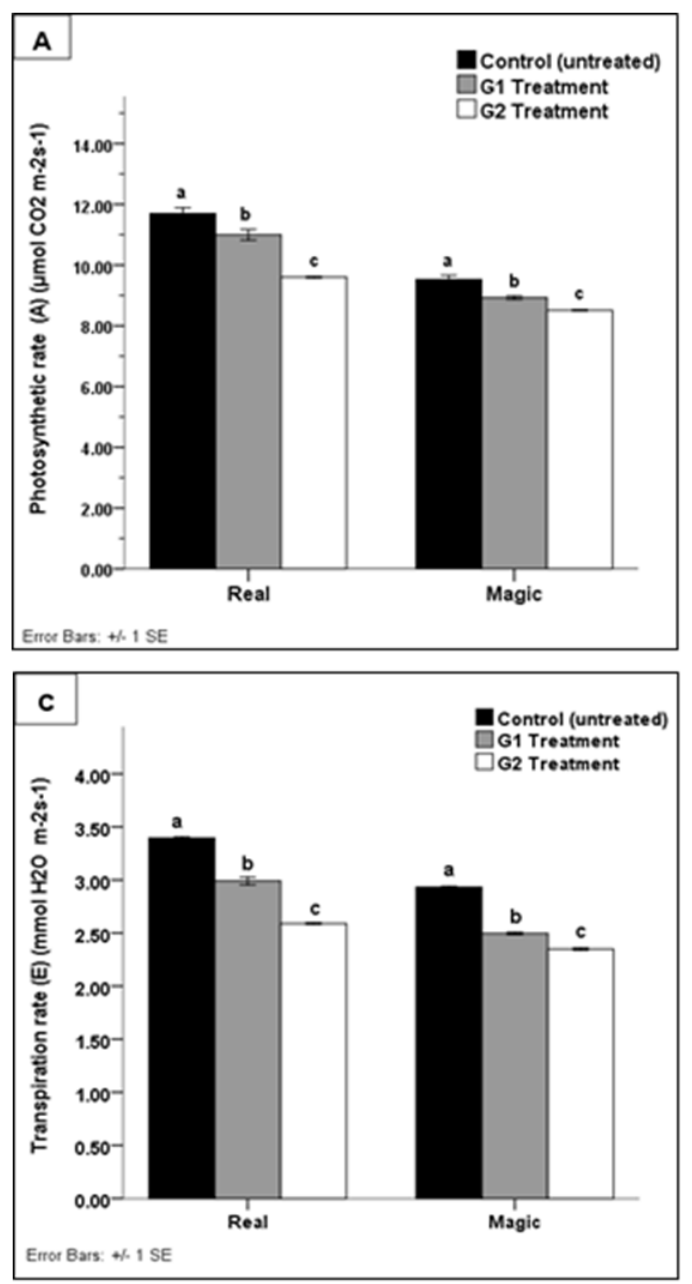

Significant differences were recorded among glycosides treatments. In both cultivars, G1 had a better effect than G2. We recorded an increase of 8-9\% in chlorophyll a amount, while in G2 treated plants, this parameter was only $4 \%$ higher. Smaller differences were also recorded in chlorophyll b content (Tab. 1).

High concentration of chlorophyll $b$ and carotenoids pigments in treated leaves could be due to the protector
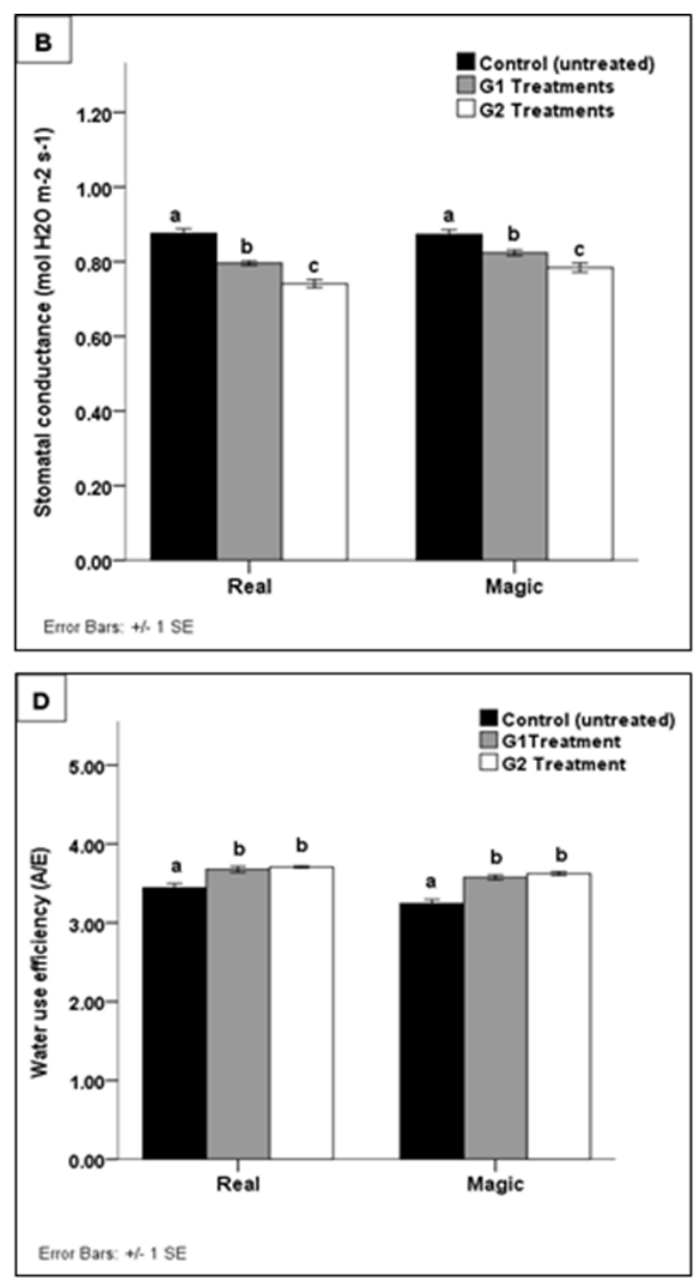

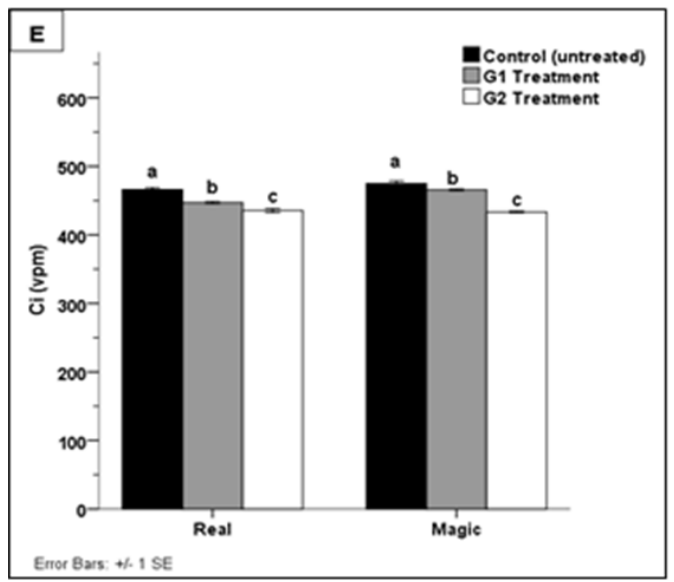

Fig. 3. Glycoside treatment influence on photosynthesis

A-Photosynthetic rate, B-Stomatal conductance, C-Transpiration rate, D-Water use efficiency (A/E), E-internal $\mathrm{CO}_{2}$ concentration 
Tab. 1. The influence of furostanol glycoside treatment on chlorophylls and carotenoids content at two strawberry cultivars

\begin{tabular}{ccccccc}
\hline Cultivar & Variant & $\begin{array}{c}\text { Chlorophyll } \\
\text { a mg/g d.w. }\end{array}$ & $\begin{array}{c}\text { Chlorophyll } \\
\text { b mg/gd.w. }\end{array}$ & $\begin{array}{c}\text { Carotenoids } \\
\text { mg/g d.w. }\end{array}$ & Chl. a/ Chl. b & Total Chlorophyll \\
\hline \multirow{2}{*}{ 'Real' } & Control & $2.74^{\mathrm{a}} \pm 0.06$ & $1.18^{\mathrm{a}} \pm 0.01$ & $0.85^{\mathrm{a}} \pm 0.01$ & $2.32^{\mathrm{a}} \pm 0.03$ & $3.92^{\mathrm{a}} \pm 0.07$ \\
& G1 treatment & $2.95^{\mathrm{b}} \pm 0.02$ & $1.36^{\mathrm{b}} \pm 0.02$ & $1.05^{\mathrm{b}} \pm 0.01$ & $2.18^{\mathrm{b}} \pm 0.03$ & $4.30^{\mathrm{b}} \pm 0.02$ \\
& G2 treatment & $2.84^{\mathrm{a} b \mathrm{~b}} \pm 0.01$ & $1.33^{\mathrm{b}} \pm 0.01$ & $0.98^{\mathrm{c}} \pm 0.02$ & $2.13^{\mathrm{b}} \pm 0.02$ & $4.17^{\mathrm{b}} \pm 0.01$ \\
\hline \multirow{3}{*}{ 'Magic' } & Control & $2.73^{\mathrm{a}} \pm 0.01$ & $1.10^{\mathrm{a}} \pm 0.01$ & $0.85^{\mathrm{a}} \pm 0.02$ & $2.48^{\mathrm{a}} \pm 0.03$ & $3.84^{\mathrm{a}} \pm 0.01$ \\
& G1 treatment & $2.95^{\mathrm{b}} \pm 0.01$ & $1.25^{\mathrm{b}} \pm 0.01$ & $1.11^{\mathrm{b}} \pm 0.02$ & $2.37^{\mathrm{b}} \pm 0.01$ & $4.20^{\mathrm{b}} \pm 0.01$ \\
& G2 treatment & $2.84^{\mathrm{c}} \pm 0.01$ & $1.19^{\mathrm{c}} \pm 0.01$ & $0.72^{\mathrm{c}} \pm 0.03$ & $2.39^{\mathrm{b}} \pm 0.01$ & $4.02^{\mathrm{c}} \pm 0.01$ \\
\hline
\end{tabular}

Note: Values in the same row and subtable not sharing the same subscript are significantly different at $p<, 05$ in the two-sided test of equality for column means. Cells with no subscript are not included in the test. Tests assume equal variances

effect of glycosides against chlorophyll molecules degradation by improving water use efficiency, as a consequence of reduction in leaf transpiration rate caused by stomata closure (Shanan and Shalaby, 2011). Enhancing of chlorophyll $\mathrm{b}$ and carotenoids is usually associated with an increase in photosynthetic antenna size, which leads to a better energy transfer as an adaptive reaction to the different environmental conditions (Chartzoulakis et al., 1993; Pirzad et al., 2011). This may suggest that foliar spraying with G2 may induce a suite of physiological adaptations related to stomatal limitation, which may confer a degree of stress tolerance and aid in the recovery from stress-induced damage.

It is known that photosynthetic efficiency depends on chlorophyll content as well as stomatal response. Previous results on furostanol glycoside effects report only that foliar spraying enhances biosynthesis of assimilator pigment content (Muntenau et al., 2008; Vasil'eva et al., 2003), without any concrete statements about their implications in photosynthesis. Our results showed that glycoside treatments induced a decrease in photosynthetic rate (A) by $6 \%$ in G1 treated plants and by $15-20 \%$ in G2 treated ones (Fig. 3A). These reductions (especially of G2 treated plants) are associated with those of stomatal conductance, which decreased by $6-9 \%$ in G1 treated plants and by $10-$ $15 \%$ in G2 treated ones (Fig. 3B). Stomatal conductance reduction depleted diffusion of $\mathrm{CO}_{2}$ through mesophyll cell walls, membranes, cytoplasm, and chloroplast wall, leading to decreases in internal $\mathrm{CO}_{2}$ concentration $(\mathrm{Ci})$ by $4 \%$ in G1 treated plants and 8\% in G2 treated ones (Fig. 3E).

On the other hand, glycoside treatment determined a decrease in evapotranspiration rate (E) by $12-15 \%$ in G1 treated plants and by $20-25 \%$ in G2 treated ones (Fig. 3C) which led to increase of water use efficiency (A/E) by $7-11 \%$ (Fig. 3D). The similar effect on improving of $\mathrm{A} / \mathrm{E}$ by decreases in photosynthetic rate as a consequence of stomatal limitation was shown in experiments with white spruce (Fuchs et al., 1999) and pepper (del Amor et al., 2011) treated with antitranspirant substances like ABA and $\mathrm{ABA}$ analogues. Therefore, we presume that our furostanol glycoside treatments may have antitranspirant effect by stomatal limitation of photosynthesis in both 'Real' and 'Magic' cultivar.

However, it has been observed that stomatal limitation was stronger in 'Real', which recorded a $\mathrm{g}_{\mathrm{s}}$ decrease by
9-15\%, than 'Magic' for which $g_{s}$ was only 6-10\% lower. This led to a higher limitation of $\mathrm{CO}_{2}$ availability for the mesophyll of leaves and to $5 \%$ higher decrease in photosynthetic rate with 'Real' than in 'Magic'. This hypothesis will need further investigations in experiments with drought and classic antitranspirants.

\section{Conclusions}

The present study showed a significant positive effect of furostanol glycosides on rooting processes and root system growth and development of young daughter strawberry plants when it was applied in $0.3 \mathrm{mM}$ concentration. Although the foliar application of both products seemed to exhibit bioactive properties as they were able to significantly stimulate the root system development, G1 was often more effective than $G 2$ in improving the new leaves formation, growth and photosynthetic pigments content. The decline in assimilation rates was observed in both glycoside treated plants, smaller in G1 compared with G2. However, this decrease was associated with better water use efficiency and better use of internal carbon dioxide, which suggests an antitranspirant action. Work is in progress to investigate the effect that furostanol glycosides have in allowing tissues to dehydrate and then recover.

\section{Acknowledgements}

The present contribution was supported by the POSDRU Contract no.89/1.5/S/62371. We thank Biological Research Institute for the glycosides put at our disposal.

\section{References}

Aminifard MH, Aroiee H, Fatemi H, Ameri A, Karimpour S (2010). Responses of eggplant (Solanum melongena L.) to different rates of nitrogen under field conditions. J Central Europ Agric 11(4):453-458.

Arthan D, Kittakoop P, Esen A, Svasti J (2006). Furostanol glycoside 26-O-beta-glucosidase from the leaves of Solanum torvum. Phytochemistry 67(1):27-33.

Aswar U, Bodhankar SL, Mohan V, Thakurdesai PA (2010). Effect of furostanol glycosides from Trigonella foenum-graecum on the reproductive system of male albino rats. Phytother $\operatorname{Res}(10): 1482-8$.

Bañón S, Martínez JJ, Fernández JA, Ochoa J, González A (2003). Effect of indolebutyric acid and paclobutrazol on 
the rooting of Rhamnus alaternus stem cuttings. Proc. 6th IS on Protected Cult. Acta Hort 614.

Blunden G, Jenkins T, Liu Y-W (1997). Enhanced leaf chlorophyll levels in plants treated with seaweed extract. J Appl Phycol 8:535-54.

Boehme M, Schevtschenko J, Pinker I (2005). Effect of biostimulators on growth of vegetables in hydroponical systems. Acta Hort 697:337-344.

Botta A, Marin C, Piñol R, Ruz L, Badosa E, Montesinos E (2009). Study of the mode of action of Inicium, a product developed specifically to overcome transplant stress in strawberry plants. Acta Hort 842:721-724.

Chartzoulakis K, Noitsakis B, Therios I (1993). Photosynthesis, plant growth and dry matter distribution in kiwifruit as influenced by water deficits. Irrigation Sci 14:1-5.

Christov C, Tsvetkov I, Kovachev V (1995). Use of paclobutrazol to control vegetative growth and improve fruiting efficiency of grapevines (Vitis vinifera L.). Bulg J Plant Physiol 21(4):64-71.

Del Amor FM, Cuadra-Crespo P, Walker DJ, Cámara JM, Madrid R (2010). Effect of foliar application of antitranspirant on photosynthesis and water relations of pepper plants under different levels of $\mathrm{CO}_{2}$ and water stress. J Plant Physiol 167(15):1232-8.

Deyton DE, Sams CE, Cummins JC (1991). Strawberry growth and photosynthetic responses to paclobutrazol. HortSci 26(9):1178-1180.

Fuchs EE, Livingston NJ, Abrams SR, Rosa PA (1999). Structure activity relationships of ABA analogs based on their effects on the gas exchange of clonal white spruce (Picea glauca) amblings. Physiologia Plant 105:245-255.

Górnik K, Grzesik M, Romanowska-Duda B (2008). The effect of chitosan on rooting of grapevine cuttings and on subsequent plant growth under drought and temperature stress. J Fruit Ornam Plant Res 16:333-343.

Khalil IA (1995). Chlorophyll and carotenoid contents in cereals as affected by growth retardants of triazole series. Cereal Res Comm 23:183-189.

Kirmizibekmez H, Taşdemir D, Ersöz T, Ireland CM, Caliş I (2002). A new pregnane glycoside and a furostanol glycoside from Digitalis cariensis. Pharmazie 57(10):716-720.

Laugale V, Lepse L, Daugavietis M (2006). Using of growth stimulator 'Ausma' in strawberry plant production. Latv J Agronomy 9:64-68.

Lichtenthaler HK (1987). Chlorophylls and carotenoids: pigments of photosynthetic biomembranes. Methods Enzymol 148:350-382.

Liu HW, Wang SL, Cai B, Qu GX, Yang XJ, Kobayashi H, Yao XS (2003). New furostanol glycosides from the rhizomes of Dioscorea futschauensis R. Kunth. J Asian Nat Prod Res (4):241-247.

Munteanu N, Iurea D, Mustea M (2008). Improving the vine crop technologies by using glycoside substances, under conditions of economic efficiency and environmental protection. Cercetări Agronomice în Moldova XLI(3):135.
Napolitano A, Muzashvili T, Perrone A, Pizza C, Kemertelidze E, Piacente $S$ (2011). Steroidal glycosides from Ruscus ponticus. Phytochemistry 72(7):651-661.

Neri D, Lodolini EM, Savini G, Sabbatini P, Bonanomi G, Zucconi $F$ (2002). Foliar application of humic acids on strawberry (cv. 'Onda'). Acta Hort 594:297-302.

Peng J, Yao X, Kobayashi H, Ma C (1995). Novel furostanol glycosides from Allium macrostemon. Planta Med 61(1):58-61.

Pirzad A, Shakiba MR, Zehtab-Salmasi S, Mohammadi SA, Darvishzadeh R, Samadi A (2011). Effect of water stress on leaf relative water content, chlorophyll, proline and soluble carbohydrates in Matricaria chamomilla L. J Med Plants Res 5(12):2483-2488.

Pise NM, Sabale AB (2010). Effect of seaweed concentrates on the growth and biochemical constituents of Trigonella foenum-graecum L. J Phytol 2(4):50-56.

Rosier CL, Frampton J (2004). Growth stage, auxin type, and concentration influence rooting of stem cuttings of fraser fir. HortSci 39(6):1397-1402.

Sarli G, De Lisi A, Montesano V, Schiavione D (2009). Evaluation of biostimulating products on strawberry in southern Italy. Acta Hort 842:805-808.

Sas-Paszt L, Żurawicz E, Masny A, Filipczak J, Pluta S, Lewandowski M, Basak A (2008). The use of biostimulators in small fruit growing, 76-90 p. In: Sadowski A (Ed.). Biostimulators in modern agriculture in fruit crops, Monographs series, Wieś Jutra, Warszawa.

Sebastian B, Alberto G, Emillo AC, Jose AF, Juan AF (2002). Growth development and color response of potted Dianthus caryophyllus to paclobutrazol treatment. Sci Hort 1767:17.

Shanan NT, Shalaby EA (2011). Influence of some chemical compounds as antitranspirant agents on vase life of Monstera deliciosa leaves. Afr J Agric Res 6(1):132-139.

Thirumaran G, Arumugam M, Arumugam R, Anantharaman P (2009). Effect of seaweed liquid fertilizer on growth and pigment concentration of Abelmoschus esculentus. Am-Eur J Agron 2(2):57-66.

Vasil'eva IS, Vanyushkin SA, Zinov'eva SV, Udalova Zh V, Bolychevtseva Yu V, Paseshnichenko VA (2003). Photosynthetic pigments of tomato plants under conditions of biotic stress and effects of furostanol glycosides. Appl Biochem Microbiol 39(6):606-612.

Vasil'eva IS, Vanyushkin SA, Zinov'eva SV, Udalova Zh V, Volkova LA, Nosov AM, Paseshnichenko VA (2005). Adaptogenic effects of furostanol glycosides of Dioscorea deltoidea wall on oxidative processes in tomato plants during biotic stress. Appl Biochem Microbiol 41(3):306-311.

Volkova LA, Maevskaya SN, Burgutin AB, Nosov AM (2007). Effect of exogenous steroid glycosides on cultured cells of potato under oxidative stress. Russ J Plant Physiol 54(5):639-645.

Yahara S, Ura T, Sakamoto C, Nohara T (1994). Steroidal glycosides from Capsicum annuum. Phytochemistry 37(3):831835. 